\title{
High-Efficiency Glass and Printable Flexible Dye-Sensitized Solar Cells with Water-Based Electrolytes
}

\author{
Omar Moudam ${ }^{1}$ and Silvia Villarroya-Lidon ${ }^{2}$ \\ ${ }^{1}$ School of Electronic Engineering, University of Bangor, Dean Street, Gwynedd, Bangor LL57 1UT, UK \\ ${ }^{2}$ G24 Innovations Limited, Wentloog Environmental Centre, Cardiff CF3 2GH, UK \\ Correspondence should be addressed to Omar Moudam; o.moudam@bangor.ac.uk
}

Received 6 May 2014; Accepted 28 July 2014; Published 13 August 2014

Academic Editor: M. S. A. Abdel-Mottaleb

Copyright (c) 2014 O. Moudam and S. Villarroya-Lidon. This is an open access article distributed under the Creative Commons Attribution License, which permits unrestricted use, distribution, and reproduction in any medium, provided the original work is properly cited.

\begin{abstract}
The performance of a flexible and glass dye-sensitized solar cell (DSSC) with water-based electrolyte solutions is described. High concentrations of alkylamidazoliums were used to overcome the deleterious effect of water and, based on this variable, pure waterbased electrolyte DSSCs were tested displaying the highest recorded efficiency so far of $3.45 \%$ and $6 \%$ for flexible and glass cells, respectively, under a simulated air mass 1.5 solar spectrum illumination at $100 \mathrm{mWcm}^{-2}$. An improvement in the $J_{\mathrm{sc}}$ with high water content and the positive impact of GuSCN on the enhancement of the performance of pure water-based electrolytes were also observed.
\end{abstract}

\section{Introduction}

Dye-sensitized solar cells (DSSCs) are considered so far to be the best low cost alternative to silicon photovoltaic cells [1-3] demonstrating an efficiency of up to $12 \%$ [4] and have been intensively studied since their discovery in 1991 [5]. The underlying process for this technology relies upon a sensitizing dye adsorbed onto the surface of a very thin, porous, ceramic-like sponge made of titanium dioxide $\left(\mathrm{TiO}_{2}\right)$, a commonly available material. The dye traps light and then uses this energy to inject an electron into the $\mathrm{TiO}_{2}$. These electrons become available for producing useful electricity when the $\mathrm{TiO}_{2}$ is connected through an external load, such as a battery, light, or other electrical devices, thus closing the circuit so that the electrons are returned back to the dye. The flexible DSSC modules are made of thin and flexible polymers or foils, which are tough, durable, safe to use, and environmentally friendly since the electricity produced is clean and the manufacturing processes are based on abundant, recyclable materials. However, water can permeate into the device relatively rapidly due to the flexible plastic design as opposed to glass. Permeation can be reduced by barrier layers, but this increases the cost. Water was frequently used as an electrolyte in early DSSCs but was abandoned in favour of organic solvents that gave much higher cell efficiencies. In the past, many reports were of the opinion that water was poisonous for DSSCs and that the presence of even a slight trace of water in the electrolyte would be detrimental to the cell performance and would reduce cell stability either by dye detachment [6], by formation of iodate [7], or by a decrease in electron life-time [8]. Recently, however, it has been thought that water-based DSSCs could be relevant to DSSC development since cells, properly optimized to work with water, can give reasonable efficiencies [9] and display other advantages. The highest published efficiencies for $100 \%$ water-based electrolyte cells made using 1 sun have increased slightly from $1.1 \%$ [10] to $2.4 \%$ [9] and to $4 \%$ [11], and recent work based on water gel polymer shows that efficiencies of $2.1 \%$ [12] and $4.78 \%$ [13] were achieved. These results could justify the return to reexamining water as a less expensive and more environmentally friendly alternative for DSSCs. To our knowledge, while the focus was previously on glass cells, $100 \%$ water-based electrolytes remained untested at 1 sun for printable flexible DSSCs. Law et al. [9] reported that a waterbased organic electrolyte with the following formulation: $2 \mathrm{M}$ 1-propyl-3-methylimidazolium iodide (PMIM I), $0.05 \mathrm{M}$ iodine, $0.1 \mathrm{M}$ guanidinium thiocyanate (GuSCN), and $0.5 \mathrm{M}$ tert-butylpyridine (TBP), functioned without efficiency loss 
with up to $40 \%$ water fraction but it decreased significantly at $60 \%$ water fraction. Another study [11] showed that for a pure water electrolyte with a high concentration of guanidinium iodide GuI $8 \mathrm{M}$ (its stability has not yet been demonstrated and it is not commercially available, thus increasing the cost) it was possible to achieve an efficiency of $4 \%$ by adding more additives to the electrolyte formulations to improve the wetting of the $\mathrm{TiO}_{2}$. Out of interest, we prepared pure water electrolytes with a concentration of different alkylimidazolium derivatives slightly higher than $2 \mathrm{M}$ varying from $3 \mathrm{M}$ to $4 \mathrm{M}$ (1.4 M for BMIM-I for our standard electrolyte) in order to overcome the deleterious effect and by doing so we were able to avoid the phase segregation and to achieve an efficiency of $3.45 \%$ and $6 \%$ for flexible and glass cells, respectively, in $100 \%$ water-based DSSC. This work is presented in two parts. In the first part, we test water content electrolytes for flexible cells only since glass cells were already tested in a previous study. We present detailed measurements of cell characteristics versus water content to observe the influence of water on flexible cells. In the second part, we test both glass and flexible cells with pure water electrolytes with different formulations; DSSCs show an improvement in performance compared to those with aqueous and organic electrolytes. Also presented in this work is a study of the life-time performances for water-based DSSCs under soaking illumination.

\section{Experimental}

1-Propyl-3-methylimidazolium iodide PMIM-I, 1-butyl-3methylimidazolium iodide BMIM-I, 1-propyl-3-methylimidazolium bis-(trifluoromethanesulfonyl)-imide PMIM-TFSI, 1-butyl-3-methylimidazolium bis-(trifluoromethanesulfonyl)-imide BMIM-TFSI, 1-ethyl-3-methylimidazolium bis(trifluoromethanesulfonyl)-imide EMIM-TFSI, and N-butylbenzimidazole BBI were purchased from BASF; 4-tert-butylpyridine TBP, guanidinium thiocyanate GuSCN, iodine, sulfolane, and other solvents were purchased from SigmaAldrich; deionized water was purchased from ReAgent (conductivity $<1 \mu \mathrm{S} / \mathrm{cm}$ ); the ruthenium dye $\mathrm{Z} 907$, titanium foil, scattering $\mathrm{TiO}_{2}$ nanoparticle paste, plastic counter electrode platinum-sputtered ITO/PET (PET: polyethylene terephthalate) $/ 15 \Omega / \mathrm{cm}^{2}$, glass platinum-sputtered ITO/FTO (FTO: fluorine-doped tin oxide) $/ 15 \Omega / \mathrm{cm}^{2}$, 4-guanidinobutyric acid (GBA), hydrogen hexachloroplatinate (IV) hydrate $\left(\mathrm{H}_{2} \mathrm{PtCl}_{6} \cdot \mathrm{H}_{2} \mathrm{O}\right)$, iodine, and 2-propanol were offered by G24i.

Glass cells were fabricated using standard procedures. The $\mathrm{TiO}_{2}$ films were made from colloidal solutions using a screen printing method and then heated to $500^{\circ} \mathrm{C}$ for 30 minutes. Two layers were deposited successively: a $4 \mu \mathrm{m}$ thick transparent layer followed by a $4 \mu \mathrm{m}$ lightscattering layer of nanocrystalline $\mathrm{TiO}_{2}$. Dyeing was done using $24 \mathrm{mM}: 24 \mathrm{mM}: \mathrm{Z} 907: \mathrm{GBA}$ solutions in an alcoholbased solvent for 5 minutes. The counter electrodes were fabricated by applying $8 \mathrm{mM} \mathrm{H}_{2} \mathrm{PtCl}_{6}$ in 2-propanol to the FTO glass, followed by heating in an oven at $500^{\circ} \mathrm{C}$ for 30 minutes. Cell assemblies were formed by sealing the counter electrodes to the $\mathrm{TiO}_{2}$ electrode with Surlyn (Dupont) at $100^{\circ} \mathrm{C}$ for 1 minute. The corresponding electrolyte was introduced through two small holes, previously drilled through the counterelectrode, which were then sealed with Surlyn. Photocurrent versus voltage characteristics were measured with a Keithley 2602 sourcemeter and a LED solar simulator illuminated. The irradiated area of the cell was $0.3 \mathrm{~cm}^{2}$.

Flexible cells were fabricated using standard procedures. The $\mathrm{TiO}_{2}$ nanoparticles and titanium foil were offered by G24i. Dyeing was done using $24 \mathrm{mM}: 24 \mathrm{mM}$ : Z907:GBA solutions in an alcohol-based solvent for 15 minutes. A platinum-sputtered ITO/PET was used as counter electrodes. Cell assemblies were formed by sealing the counter electrodes to the $\mathrm{TiO}_{2}$ electrode with Bynel at $150^{\circ} \mathrm{C}$ for 10 seconds. The corresponding electrolyte was introduced through the edge of the cell by capillarity using a needle. Photocurrent versus voltage characteristics were measured with a Keithley 2602 sourcemeter and a LED solar simulator illuminated. The irradiated area of the cell was $8.1 \mathrm{~cm}^{2}$.

Symmetrical cells or dummy cells were prepared by the following methods: two rectangles from the counter electrode CE film approximately $25 \mathrm{~mm} \times 35 \mathrm{~mm}$ were cut and stacked together by a thick square surlyn $25 \mathrm{~mm} \times 25 \mathrm{~mm}$ in size and a $12 \mathrm{~mm}$ diameter hole was punched using syringes. Finally, the water-based electrolytes were added into the holes using desecrator and vacuum pump and the holes were covered by silicone paste.

Cell $I-V$ characteristics were measured using illumination under AM 1.5 condition $\left(100 \mathrm{~mW} / \mathrm{cm}^{2}\right)$ from LED (Phillips LUXEON Rebel LXML-PWC2, Cool white). These LEDs cover the absorption spectra and mimic sun spectra for G24i technology. The IV data was collected from the Keithley 2602.

Life-time studies were carried out at long-term illumination at 1 sun with the Halogen lighting (Sylvania Dichroic 5130 $\left.12 \mathrm{~V} / 50 \mathrm{~W} / 60^{\circ} \mathrm{C}\right)$.

\section{Results and Discussion}

The aim was to completely remove the sulfolane solvent from the iodine/tri-iodide electrolyte and to replace it by gradually adding water. Samples were produced with different water percentages $0,5,10,20,40,60,80$, and $100 \%$ and the following ionic liquid additives BMIM-I 1.4 M, PMIM-TFSI 0.7 M, BBI $0.4 \mathrm{M}$, and $\mathrm{I}_{2} 0.1 \mathrm{M}$ were used. For comparison between the performances of different water-based electrolytes, the concentrations of the additives remained constant. Iodine was added to BMIM-I first to ensure that all the iodine ions were dissolved completely into the electrolyte; PMIMTFSI, BBI, water, and sulfolane were added to the solution and mixed at room temperature for 1 hour and then heated at $40^{\circ} \mathrm{C}$ for 1 hour. It was noted that sulfolane solidifies at room temperature; for this reason it was heated at $40^{\circ} \mathrm{C}$ to be used as a liquid for all the samples. After completing the formulation, red-brown solution electrolytes were obtained. It was observed that at $40-100 \%$ of water the solutions were not homogeneous (see Supporting Information, S1, available online at http://dx.doi.org/10.1155/2014/426785) due to nonmiscibility between water and the additives. 


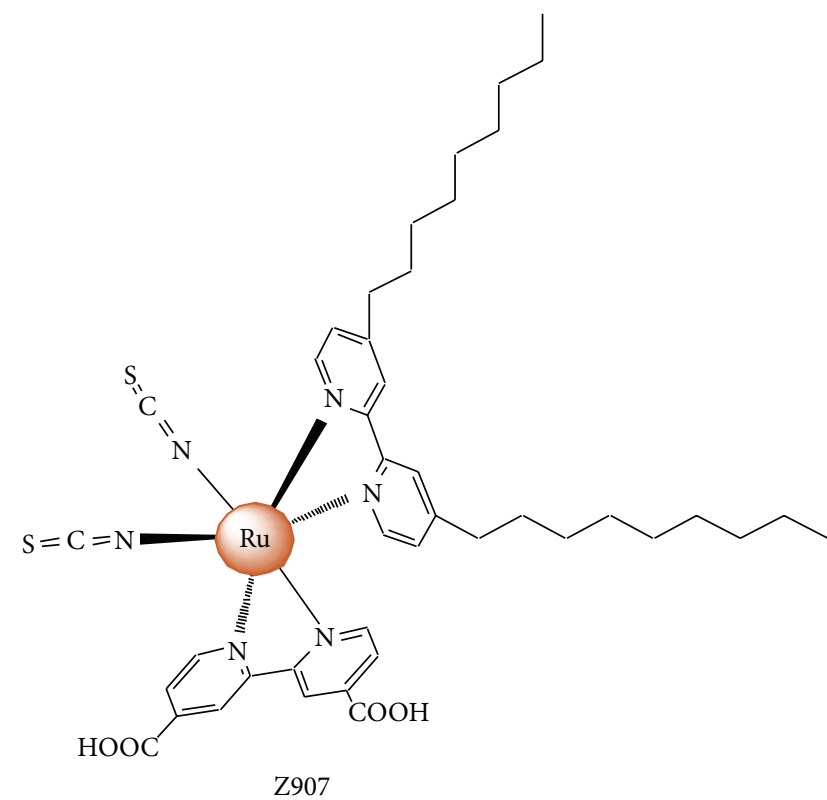

(a)

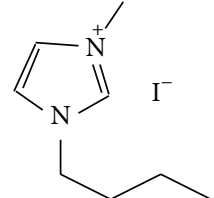

BMIM-I

FIGURE 1: Chemical structures of Z907: cis-bis(isothiocyanato) $\left(2,2^{\prime}\right.$-bipyridyl-4,4'-dicarboxylato $)\left(4,4^{\prime}\right.$-di-nonyl-2'-bipyridyl)ruthenium(II); and an example of alkylimidazolium BMIM-I: 1-butyl-3-methylimidazolium Iodide.

The solar energy-to-electricity conversion efficiency, $\eta$ (\%), of solar cells was estimated from the following equation:

$$
\eta=\frac{\left(J_{\mathrm{sc}} \times V_{\mathrm{oc}} \times \mathrm{FF}\right)}{I_{0}} \times 100
$$

where $I_{0}$ is the photon flux (ca. $100 \mathrm{~mW} / \mathrm{cm}^{2}$ for AM $1.5 \mathrm{G}$ ), $J_{\mathrm{sc}}$ is the short-circuit current density under irradiation, $V_{\text {oc }}$ is the open-circuit voltage, and FF is the fill factor. The hydrophobic dye Z907 (Figure 1) was selected in this study to avoid its desorption into the water electrolyte. Alkylimidazoliums were selected as an iodide source for these studies due to their ability to enhance the conductivity of an electrolyte containing the redox couple of $\mathrm{I}^{-} / \mathrm{I}_{3}{ }^{-}$and to increase the electron diffusion coefficient in $\mathrm{TiO}_{2}[14,15]$.

The characterization of all samples was carried out with the help of FTIR Spectroscopy Smart Germanium integrated with OMNIC software. The IR spectra of all the samples (Supporting Information, S1) present a water band at $3500 \mathrm{~cm}^{-1}$ with the absorbance increased by increasing the water quantity in the electrolyte samples. The bands' regions 500 $1500 \mathrm{~cm}^{-1}$ and $3000 \mathrm{~cm}^{-1}$ correspond to the additives present in the electrolytes. No changes were observed in the IR except that the absorbance of the electrolyte bands decreases by increasing water due to the problem of nonmiscibility between water and the additives present in the electrolyte. Water does not show a chemical reaction with the electrolyte additives especially BMIM-I, PMIM-TFSI, and BBI.

A series of cells with sulfolane and different water contents were fabricated; the photovoltaic characteristic of the water content electrolyte is summarized in Table 1 and Figure 2. Increases in photovoltaic performances by adding a small amount of water were demonstrated by Mikoshiba

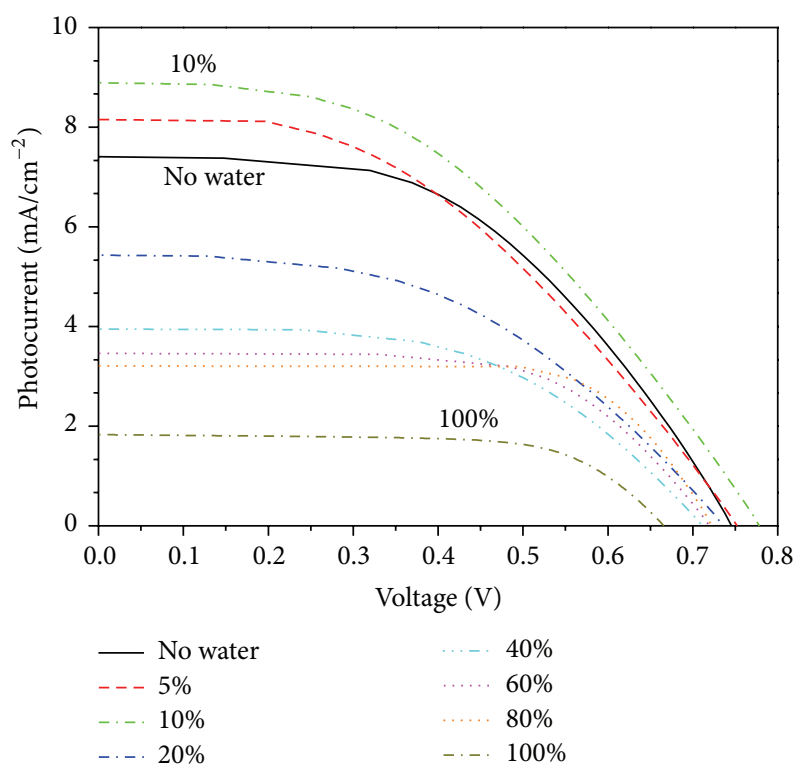

Figure 2: $I-V$ curves obtained from a water-based flexible cell with 1 sun illumination measured in the BMIM-I 1.4 M, PMIM-TFSI 0.7 M, BBI 0.4 M, I $\mathrm{I}_{2} 0.1 \mathrm{M}$, water $\%$, and sulfolane $\%$.

et al. [16]; our results show that the $10 \%$ water cell exhibits a higher efficiency than the other water-added cells. The enhancement of $V_{\text {oc }}$ afforded by the addition of $10 \%$ water is due to the reduction of the back electron transfer from the $\mathrm{TiO}_{2}$ conduction band to the $\mathrm{I}_{3}{ }^{-}$ions in the electrolyte [8], but it was found that the short circuit current $J_{\mathrm{sc}}$ and, therefore, the efficiency were limited by diffusion in cells with 
TABLE 1: Photoelectrochemical data obtained from a water-based flexible cell with 1 sun illumination measured in the BMIM-I 1.4 M, PMIMTFSI $0.7 \mathrm{M}$, BBI $0.4 \mathrm{M}, \mathrm{I}_{2} 0.1 \mathrm{M}$, water, and sulfolane.

\begin{tabular}{|c|c|c|c|c|c|}
\hline Water content [\%] & Sulfolane content [\%] & $J_{\mathrm{sc}}\left[\mathrm{mA} / \mathrm{cm}^{2}\right]$ & $V_{\mathrm{oc}}[\mathrm{V}]$ & $\mathrm{FF}$ & Efficiency [\%] \\
\hline 0 & 100 & 7.41 & 0.75 & 0.46 & 2.56 \\
\hline 5 & 95 & 8.15 & 0.75 & 0.44 & 2.69 \\
\hline 10 & 90 & 8.89 & 0.77 & 0.44 & 3.01 \\
\hline 20 & 80 & 5.43 & 0.73 & 0.48 & 1.90 \\
\hline 40 & 60 & 3.95 & 0.71 & 0.54 & 1.51 \\
\hline 60 & 40 & 3.46 & 0.72 & 0.63 & 1.57 \\
\hline 80 & 20 & 3.21 & 0.72 & 0.71 & 1.64 \\
\hline 100 & 0 & 1.83 & 0.67 & 0.70 & 0.86 \\
\hline
\end{tabular}

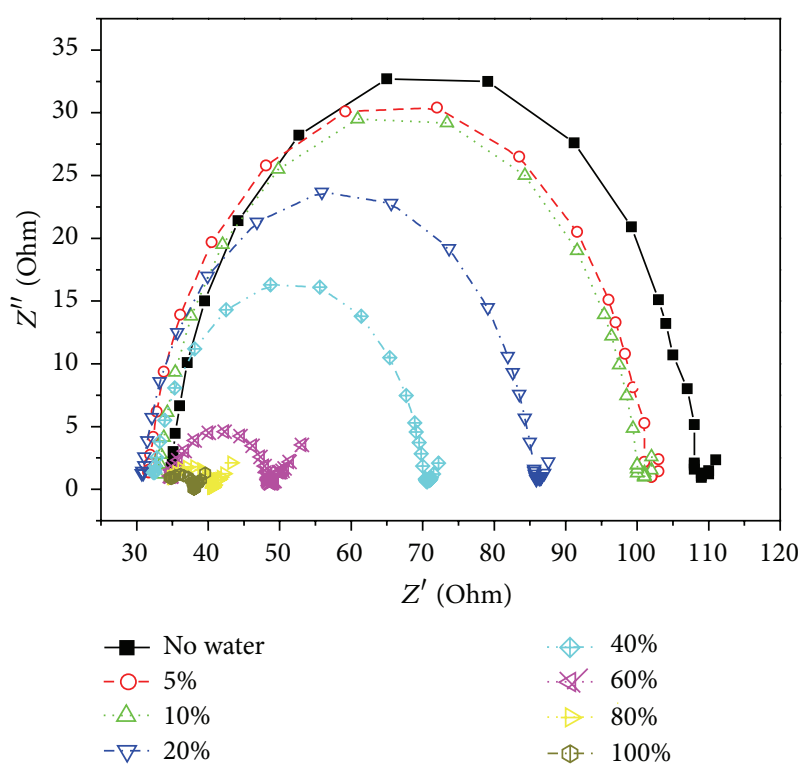

FIGURE 3: Nyquist plots of electrochemical impedance spectra containing different water-based electrolytes for symmetrical cells in dark conditions. The plots were measured with two platinumsputtered ITO/PET counter electrodes for each electrolyte and recorded over the frequency range of $0.01-10^{4} \mathrm{~Hz}$ at $V_{\text {oc }}=0 \mathrm{~V}$ with an ac amplitude of $10 \mathrm{mV}$.

a high water content. Note that the fill factor increases slightly with water content. It is known that the fill factor depends on the resistance of the $\mathrm{TiO}_{2}$ electrode, electrolyte, and counter electrode, as observed by Jung et al. [8]. The increase in the fill factor in the case of the cell with high water content is attributed to its charge transfer resistance.

To understand the decrease in $J_{\text {sc }}$, the electrochemical impedance spectroscopy was carried out. Figure 3 shows the Nyquist plots of the electrochemical cells consisting of two $\mathrm{Pt}$-coated ITO/PET counter electrodes with different water contents in the electrolyte. The corresponding charge transfer resistances, $R_{\mathrm{ct}}$, obtained by fitting the plots with IviumSoft software based on a standard Randles equivalent circuit for the frequencies from $100000 \mathrm{~Hz}$ to $0.01 \mathrm{~Hz}$, are listed in Supporting Information S2. The values of the $R_{\mathrm{ct}}$ refer to the resistance against transfer from the counter electrode to $\mathrm{I}_{3}{ }^{-}$. The results imply that the $R_{\mathrm{ct}}$ of the water-added DSSC is decreased compared to that of the nonwater DSSC (Figure 3). A lower charge transfer resistance implies a more facile electron transfer from counter electrode to $\mathrm{I}_{3}{ }^{-}$ions [8], but, contrary to that, the $J_{\mathrm{sc}}$ values of water-added DSSCs decreased. Furthermore, the viscosity of each water-added electrolyte was measured with the help of Bohlin Gemini integrated with the Bohlin software. The table (Supporting Information, S2) reveals that the addition of water decreases the viscosity of the water-added electrolyte. This decrease is considered to be favorable for the movement of the ions. The observation of this phenomenon with the addition of water is in agreement with the previous studies [8]. The decrease in $J_{\text {sc }}$ and the efficiency of the cells with high water content may be explained by several factors; for instance, the equilibrium constant at $25^{\circ} \mathrm{C}$ for the tri-iodide formation is much weaker in water than in an organic solvent [17]. Another study suggests that the injection of electrons from the dye into the $\mathrm{TiO}_{2}$ depends on the energy level matching between the excited dye molecules and the conduction band edge. It was found that the frontier electronic structure was important for the charge transfer in DSSC and that the reduction of the dye in a working DSSC involved an electron transfer from the redox couple to the oxidized dye [18]. According to Murakami et al. [10], the surface of the $\mathrm{TiO}_{2}$ showed that hydrophilicity was not high enough to allow efficient permeation of water redox electrolyte into the mesoporous structure due to the high surface tension of water compared with an organic electrolyte, whilst Law et al. [9] demonstrated that the loss of photocurrent at 1 sun light intensity is mainly due to a reduced current carrying capability of the electrolyte in the pores, not to fundamental problems with electron transfer kinetics at the $\mathrm{TiO}_{2} /$ dye/electrolyte interface. The $\mathrm{pH}$ studies were carried out (Supporting Information, S2) which clearly showed that it slightly decreases with increasing water quantities; thus, the acidity of the solutions increases. The $\mathrm{TiO}_{2}$ band edge has been shown to shift according to the Nernstian potential dependence of $60 \mathrm{mV}$ per $\mathrm{pH}$ unit in solution [19]. Other studies $[16,20]$ show that the conduction band edge of nanoporous $\mathrm{TiO}_{2}$ films shifts positively when water is added to an aprotic solution as a result of the decrease in the number of dye molecules limiting the flux of the injected electrons from the excited states of the dye and causing the decrease of $J_{\mathrm{sc}}$. 
TABle 2: Photoelectrochemical data obtained with the $100 \%$ water-based electrolyte for flexible and glass cells at 1 sun illumination.

\begin{tabular}{|c|c|c|c|c|c|c|}
\hline \multicolumn{7}{|c|}{ Flexible cells } \\
\hline $\begin{array}{l}\text { Electrolyte } \\
\text { formulation }\end{array}$ & $\begin{array}{c}\text { Water content } \\
{[\%]}\end{array}$ & Electrolyte composition & $\begin{array}{c}J_{\mathrm{sc}} \\
{\left[\mathrm{mA} / \mathrm{cm}^{2}\right]}\end{array}$ & $V_{\mathrm{oc}}[\mathrm{V}]$ & $\mathrm{FF}$ & Efficiency [\%] \\
\hline Standard & 0 & 1.4 M BMIM-I, 0.7 M PMIM-TFSI, 0.4 M BBI, 0.1 $\mathrm{M} \mathrm{I}_{2}$ & 7.41 & 0.75 & 0.46 & 2.56 \\
\hline IC100 & 100 & 4 M PMIM-I, 0.2 M GuSCN, 0.1 $\mathrm{M} \mathrm{I}_{2}, 1.2 \mathrm{M} \mathrm{tBP}$ & 7.45 & 0.77 & 0.60 & 3.45 \\
\hline PE100 & 100 & 3.8 M PMIM-I, 0.7 M EMIM-TFSI, 0.1 $\mathrm{M} \mathrm{I}_{2}, 0.4 \mathrm{M}$ BBI & 6.95 & 0.74 & 0.56 & 2.88 \\
\hline PB100 & 100 & 3.6 M PMIM-I, 0.7 M BMIM-TFSI, 0.1 M I, $0.4 \mathrm{M}$ BBI & 7.01 & 0.74 & 0.59 & 3.05 \\
\hline \multicolumn{7}{|c|}{ Glass cells } \\
\hline Standard & 0 & 1.4 M BMIM-I, 0.7 M PMIM-TFSI, 0.4 M BBI, 0.1 M I & 9.97 & 0.78 & 0.53 & 4.12 \\
\hline IC100 & 100 & 4 M PMIM-I, 0.2 M GuSCN, 0.1 M I $2,1.2 \mathrm{M} \mathrm{tBP}$ & 11.01 & 0.79 & 0.69 & 6.00 \\
\hline PE100 & 100 & 3.8 M PMIM-I, 0.7 M EMIM-TFSI, 0.1 M I, $0.4 \mathrm{M}$ BBI & 9.48 & 0.75 & 0.65 & 4.62 \\
\hline PB-100 & 100 & 3.6 M PMIM-I, 0.7 M BMIM-TFSI, 0.1 M I, $0.4 \mathrm{M}$ BBI & 9.97 & 0.76 & 0.67 & 5.07 \\
\hline
\end{tabular}

Long-term stability tests were carried out on the flexible cells with various water-based electrolytes during 1,000 hours under continuous illumination at 1 sun. Life-time results are shown in Supporting Information, S3. It was observed that the $J_{\mathrm{sc}}$ for all water-based electrolytes was stable with a slight increase in the first 200 hours and stabilized thereafter until 1,000 hours. Upon completion of the life-time studies, the water-based flexible cells were examined for dye detachment using UV-Vis spectroscopy (Supporting Information, S4). No dye desorption was detected in the cells after 1000 hours under light soaking.

In the first instance, studies were carried out on electrolytes containing different water percentages with varying quantities of sulfolane from 100 to $0 \%$. The pure waterbased electrolyte did not prove to display a higher efficiency, notably $0.86 \%$ (Table 1 ). Following on from this, we were able to enhance this result by simply increasing the amount of alkylimidazolium to reduce the deleterious effect of water. For this reason, sulfolane, as an organic solvent, was eliminated from the electrolyte and only water was used. Different pure water-based electrolytes were prepared (Table 2): IC100, PE100, PB100, by using PMIM-I, as alkylimidazolium derivatives. The alkylimidazolium-bis-(trifluoromethanesulfonyl)imide (BMIM-TFSI, EMIM-TFSI) and BBI were tested as derivatives for different electrolytes and GuSCN and TBP were selected for IC100 formulation. The added quantity of the iodine $\left[I_{2}\right]=0.1 \mathrm{M}$ remained constant for all the formulations. It should be noted that the concentration of the additives for the reference electrolyte was as follows: BMIM-I 1.4 M, PMIM-TFSI 0.7 M, I $0.1 \mathrm{M}$, BBI $0.4 \mathrm{M}$ in sulfolane.

Water-based electrolyte for all formulations gives the best performance for flexible cells, with the photocurrent being about few $\mathrm{mA} / \mathrm{cm}^{2}$ more or less higher than the standard electrolyte; however, the efficiencies are within the same range with a maximum of $3.45 \%$ and $6 \%$ for flexible and glass cells, respectively. Fill factor is higher for all samples with pure water. Comparatively, pure water electrolytes tested in glass cells (Table 2) showed a high performance because the illumination at 1 sun was carried out at the back of the cell and directly on the $\mathrm{TiO}_{2}$ electrode which is not possible with the design of the flexible cells; furthermore the conductivity in the counterelectrode of the glass cells is higher than the flexible cells. The efficiencies for waterbased electrolytes in glass cells displayed the highest recorded efficiency, to date, of $6 \%$ whilst a current of $11 \mathrm{~mA} / \mathrm{cm}^{2}$ was recorded with a high voltage of $790 \mathrm{mV}$. It has been shown that pure water does not wet $\mathrm{Z907}$ dye $\mathrm{TiO}_{2}$ [21]; however, our study was carried out without the need for any surfactants like chenodeoxycholic acid as described by [22] or Triton $\mathrm{X}-100$, as a nonionic surfactant was used to enhance the water solubility [8]. However, we were able to notice the role of GuSCN to improve $J_{\text {sc }}$ and the efficiency for the IC100 formulation. Guanidinium is said to be a chaotropic ion, essentially reducing the strength of hydrophobic interactions, therefore possibly increasing wetting and diffusion limited current [23]. At the same time, the thiocyanate ion also binds iodine strongly and may thus reduce free iodine and increase collection efficiency. A previous study has found that GuSCN could improve the solar performance by slowing the surface recombination [24]. Gratzel reported that the addition of the guanidinium cation to the electrolyte could control the self-assembly of the dye at the $\mathrm{TiO}_{2}$ interface and suppress the dark current [3]. Zhang et al. demonstrated the positive effect of GuSCN on DSSC to improve the performance and stability [25]. We did notice similar performances in water with GuSCN for the IC100 formulations in flexible and glass cells.

Figure 4 presents the $I-V$ comparison performance between a standard electrolyte and a pure water IC100. High efficiencies of $3.45 \%$ and $6 \%$ were recorded for flexible and glass cells, respectively, with better performance for glass cells as previously mentioned. A significant improvement was observed in FF for the pure water electrolyte; $J_{\text {sc }}$ also increased by adding GuSCN. There did not appear to be change in the $V_{\text {oc }}$ although some studies showed that $V_{\text {oc }}$ decreases when the $\mathrm{pH}$ is acidic, which could be explained by the use of a high concentration of alkylamidazolium which neutralizes the acidity effect, thus possibly resulting in a slight improvement in the $V_{\text {oc }}$ by a few millivolts.

To complete this study, we subjected a selection of IC100 for glass water-based DSSCs to light soaking condition. Figure 5 shows long-term stability under continuous AM 


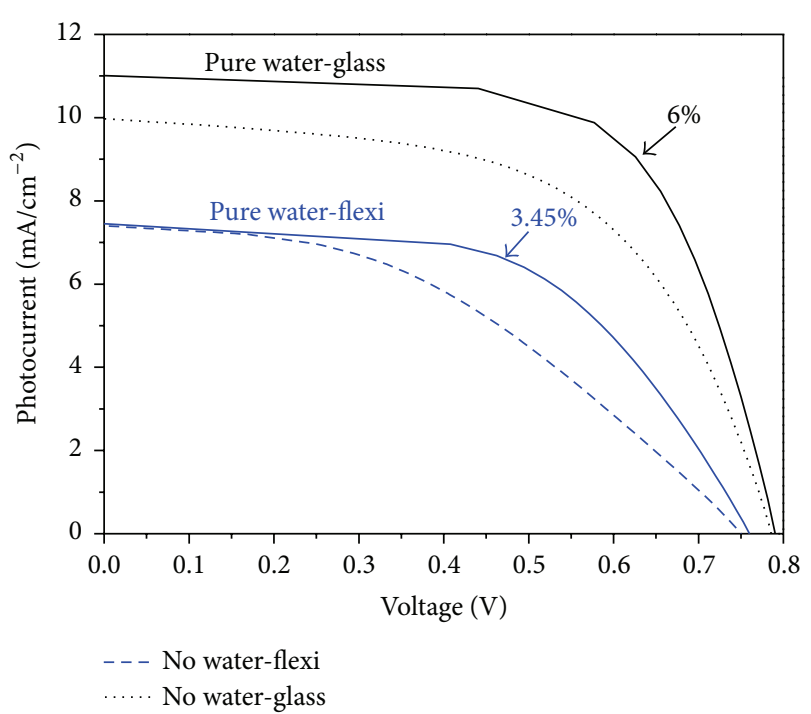

FIGURE 4: $I$ - $V$ curves obtained from a pure water electrolyte for the cell IC100 and standard electrolyte for flexible and glass cells with 1 sun illumination.

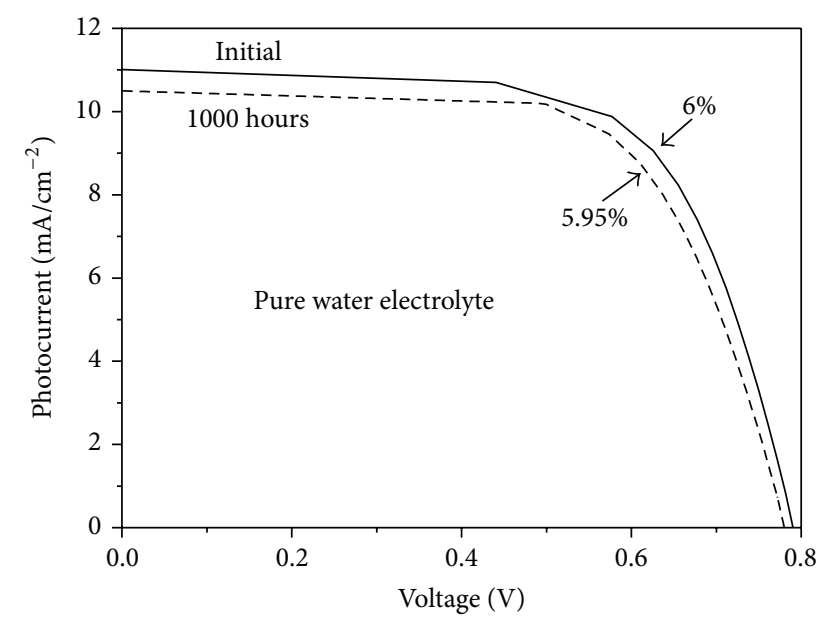

FIgURE 5: $I-V$ evolution of a IC100 under continuous illumination at 1 sun, $60^{\circ} \mathrm{C}$.

$1.5 \mathrm{G}$ irradiation. Only a $0.8 \%$ loss was recorded up to $1000 \mathrm{~h}$ under high temperature soaking at $60^{\circ} \mathrm{C}$.

\section{Conclusion}

We prepared and investigated water-based electrolyte glass and flexible DSSCs. The electrolytes containing 100\% water show a high solar cell performance of up to $3.45 \%$ for flexible cells and $6 \%$ for glass cells under simulated AM 1.5 G $\left(100 \mathrm{~mW} / \mathrm{cm}^{-2}\right)$ irradiation. To the best of our knowledge, this is the highest recorded efficiency until now and good long-term stability under continuous simulated solar light (visible-light irradiation). One of the most important features of using a high concentration of the alkylimidizolium is the reduction in the deleterious effect of water and an improvement in its miscibility with the additives present in the electrolyte, thus enhancing the solar cell's performance. The role of GuSCN in enhancing the $J_{\text {sc }}$ should also be noted. Contrary to previous works highlighting the negative effect of water, our results anticipated that water could be a good candidate for novel designed DSSCs with lower cost and environmentally friendly components.

\section{Conflict of Interests}

The authors declare that there is no conflict of interests regarding the publication of this paper.

\section{Acknowledgments}

This work was supported by the UK TSB project via Imperial College London "Water based electrolytes" (TS/I001832/1). The authors gratefully thank G24i for the provision of facilities, materials, and equipment.

\section{References}

[1] A. Hagfeldt and M. Gratzel, "Molecular photovoltaics," Accounts of Chemical Research, vol. 33, no. 5, pp. 269-277, 2000.

[2] M. K. Nazeeruddin, A. Kay, I. Rodicio et al., "Conversion of light to electricity by cis-X2bis (2,2'-bipyridyl-4,4'-dicarboxylate)ruthenium(II) charge-transfer sensitizers (X = Cl-, Br-, I-, CN-, and SCN-) on nanocrystalline titanium dioxide electrodes," Journal of the American Chemical Society, vol. 115, no. 14, pp. 6382-6390, 1993.

[3] M. Gratzel, "Conversion of sunlight to electric power by nanocrystalline dye-sensitized solar cells," Journal of Photochemistry and Photobiology A: Chemistry, vol. 164, no. 1-3, pp. 3-14, 2004.

[4] A. Yella, H. Lee, H. N. Tsao et al., "Porphyrin-sensitized solar cells with cobalt (II/III)-based redox electrolyte exceed 12 percent efficiency," Science, vol. 334, no. 6056, pp. 629-634, 2011.

[5] B. O’Regan and M. Grätzel, "A low-cost, high-efficiency solar cell based on dye-sensitized colloidal $\mathrm{TiO}_{2}$ films," Nature, vol. 353, pp. 737-740, 1991.

[6] Y. Liu, A. Hagfeldt, X. Xiao, and S. Lindquist, "Investigation of influence of redox species on the interfacial energetics of a dyesensitized nanoporous $\mathrm{TiO}_{2}$ solar cell," Solar Energy Materials and Solar Cells, vol. 55, no. 3, pp. 267-281, 1998.

[7] B. Macht, M. Turrión, A. Barkschat, P. Salvador, K. Ellmer, and $\mathrm{H}$. Tributsch, "Patterns of efficiency and degradation in dye sensitization solar cells measured with imaging techniques," Solar Energy Materials and Solar Cells, vol. 73, no. 2, pp. 163-173, 2002.

[8] Y.-S. Jung, B. Yoo, M. K. Lim, S. Y. Lee, and K.-J. Kim, "Effect of Triton X-100 in water-added electrolytes on the performance of dye-sensitized solar cells," Electrochimica Acta, vol. 54, no. 26, pp. 6286-6291, 2009.

[9] C. Law, S. C. Pathirana, X. Li et al., "Water-based electrolytes for dye-sensitized solar cells," Advanced Materials, vol. 22, no. 40, pp. 4505-4509, 2010.

[10] T. N. Murakami, H. Saito, S. Uegusa, N. Kawashima, and T. Miyasaka, "Water-based dye-sensitized solar cells: interfacial activation of $\mathrm{TiO}_{2}$ mesopores in contact with aqueous electrolyte for efficiency development," Chemistry Letters, vol. 32, no. 12, pp. 1154-1155, 2003. 
[11] C. Law, O. Moudam, S. Villarroya-Lidon, and B. O'Regan, "Managing wetting behavior and collection efficiency in photoelectrochemical devices based on water electrolytes; improvement in efficiency of water/iodide dye sensitised cells to $4 \%$," Journal of Materials Chemistry, vol. 22, no. 44, pp. 23387-23394, 2012.

[12] S. S. Soni, K. B. Fadadu, R. L. Vekariya et al., "Effect of selfassembly on triiodide diffusion in water based polymer gel electrolytes: an application in dye solar cell," Journal of Colloid and Interface Science, vol. 425, pp. 110-117, 2014.

[13] S. J. Park, K. Yoo, J.-Y. Kim et al., "Water-based thixotropic polymer gel electrolyte for dye-sensitized solar cells," ACS Nano, vol. 7, no. 5, pp. 4050-4056, 2013.

[14] S. Kambe, S. Nakade, T. Kitamura, Y. Wada, and S. Yanagida, "Influence of the electrolytes on electron transport in mesoporous $\mathrm{TiO}_{2}$-electrolyte systems," Journal of Physical Chemistry B, vol. 106, no. 11, pp. 2967-2972, 2002.

[15] W. Kubo, S. Kambe, S. Nakade et al., "Photocurrent-determining processes in quasi-solid-state dye-sensitized solar cells using ionic gel electrolytes," Journal of Physical Chemistry B, vol. 107, no. 18, pp. 4374-4381, 2003.

[16] S. Mikoshiba, S. Murai, H. Sumino, T. Kado, D. Kosugi, and S. Hayase, "Ionic liquid type dye-sensitized solar cells: increases in photovoltaic performances by adding a small amount of water," Current Applied Physics, vol. 5, no. 2, pp. 152-158, 2005.

[17] L. I. Katzin and E. Gebert, "The iodide-iodine-triiodide equilibrium and ion activity coefficient ratios," Journal of the American Chemical Society, vol. 77, no. 22, pp. 5814-5819, 1955.

[18] M. Hahlin, E. M. J. Johansson, R. Schölin, H. Siegbahn, and H. Rensmo, "Influence of water on the electronic and molecular surface structures of ru-dyes at nanostructured $\mathrm{TiO}_{2}$," Journal of Physical Chemistry C, vol. 115, no. 24, pp. 11996-12004, 2011.

[19] G. Rothenberger, D. Fitzmaurice, and M. Grätzel, "Spectroscopy of conduction band electrons in transparent metal oxide semiconductor films: optical determination of the flatband potential of colloidal titanium dioxide films," The Journal of Physical Chemistry, vol. 96, no. 14, pp. 5983-5986, 1992.

[20] B. Enright, G. Redmond, and D. Fitzmaurice, "Spectroscopic determination of flatband potentials for polycrystalline $\mathrm{TiO}_{2}$ electrodes in mixed solvent systems," Journal of Physical Chemistry, vol. 98, no. 24, pp. 6195-6200, 1994.

[21] M. K. Wang, S. J. Moon, D. F. Zhou et al., "Enhanced-lightharvesting amphiphilic ruthenium dye for efficient solid-state dye-sensitized solar cells," Advanced Functional Materials, vol. 20, no. 11, pp. 1821-1826, 2010.

[22] J. H. Yum, S. J. Moon, R. Humphry-Baker et al., "Effect of coadsorbent on the photovoltaic performance of squaraine sensitized nanocrystalline solar cells," Nanotechnology, vol. 19, no. 42, Article ID 424005, 2008.

[23] P. H. von Hippel and K. Wong, "Neutral salts: the generality of their effects on the stability of macromolecular conformations," Science, vol. 145, no. 3632, pp. 577-580, 1964.

[24] S. Y. Huang, G. Schlichthrol, A. J. Nozik, M. Gratzel, and A. J. Frank, "Charge recombination in dye-sensitized nanocrystalline $\mathrm{TiO}_{2}$ solar cells," The Journal of Physical Chemistry $\mathrm{B}$, vol. 101, no. 14, pp. 2576-2582, 1997.

[25] C. Zhang, Y. Huang, Z. Huo, S. Chen, and S. Dai, "Photoelectrochemical effects of guanidinium thiocyanate on dye-sensitized solar cell performance and stability," Journal of Physical Chemistry C, vol. 113, no. 52, pp. 21779-21783, 2009. 


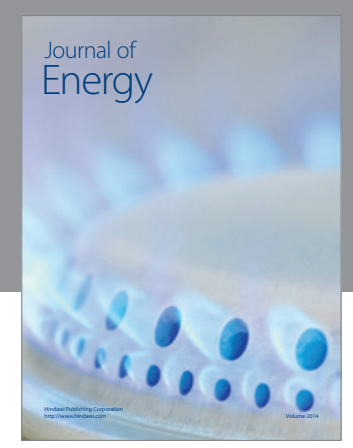

Journal of

Industrial Engineering
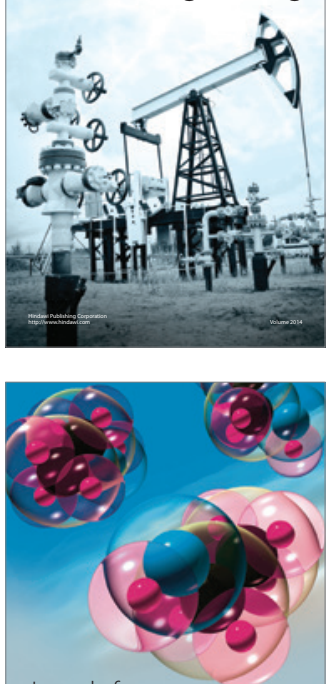

Fuels
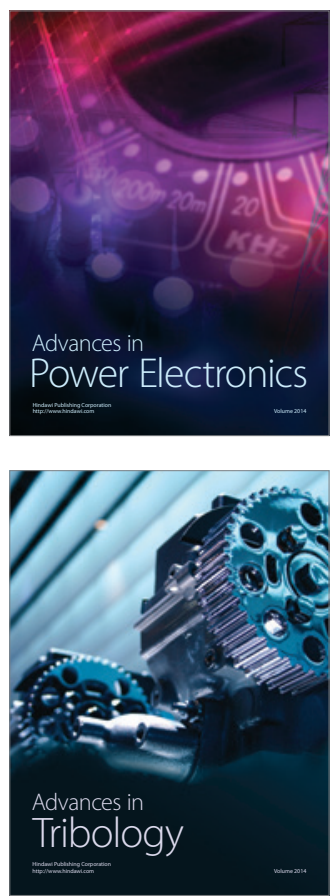

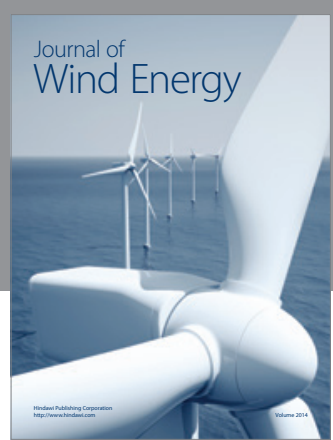

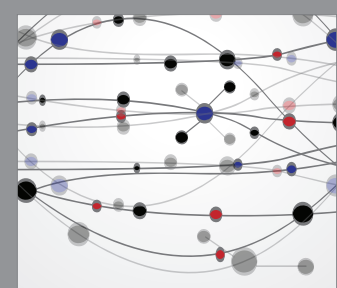

The Scientific World Journal

Submit your manuscripts at http://www.hindawi.com

Journal of

Structures
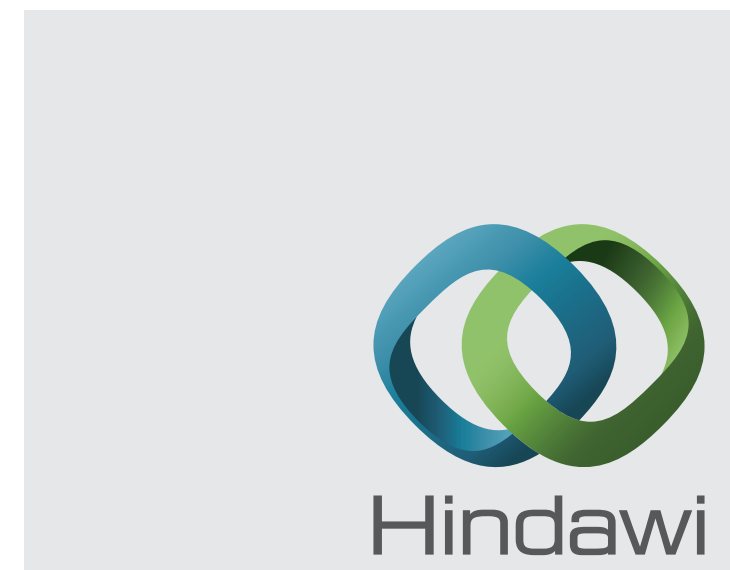

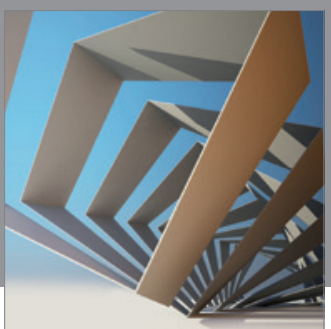

Rotating

Machinery
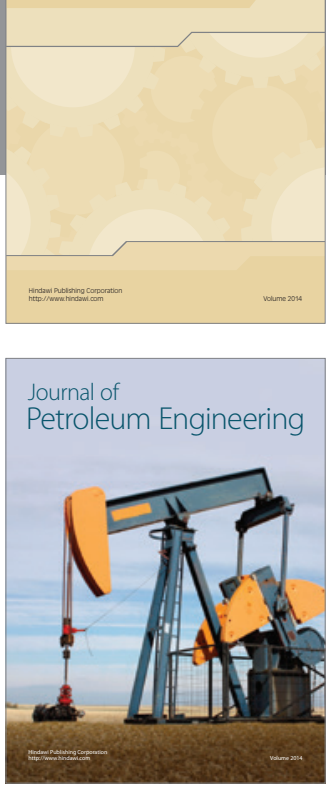

Journal of

Solar Energy
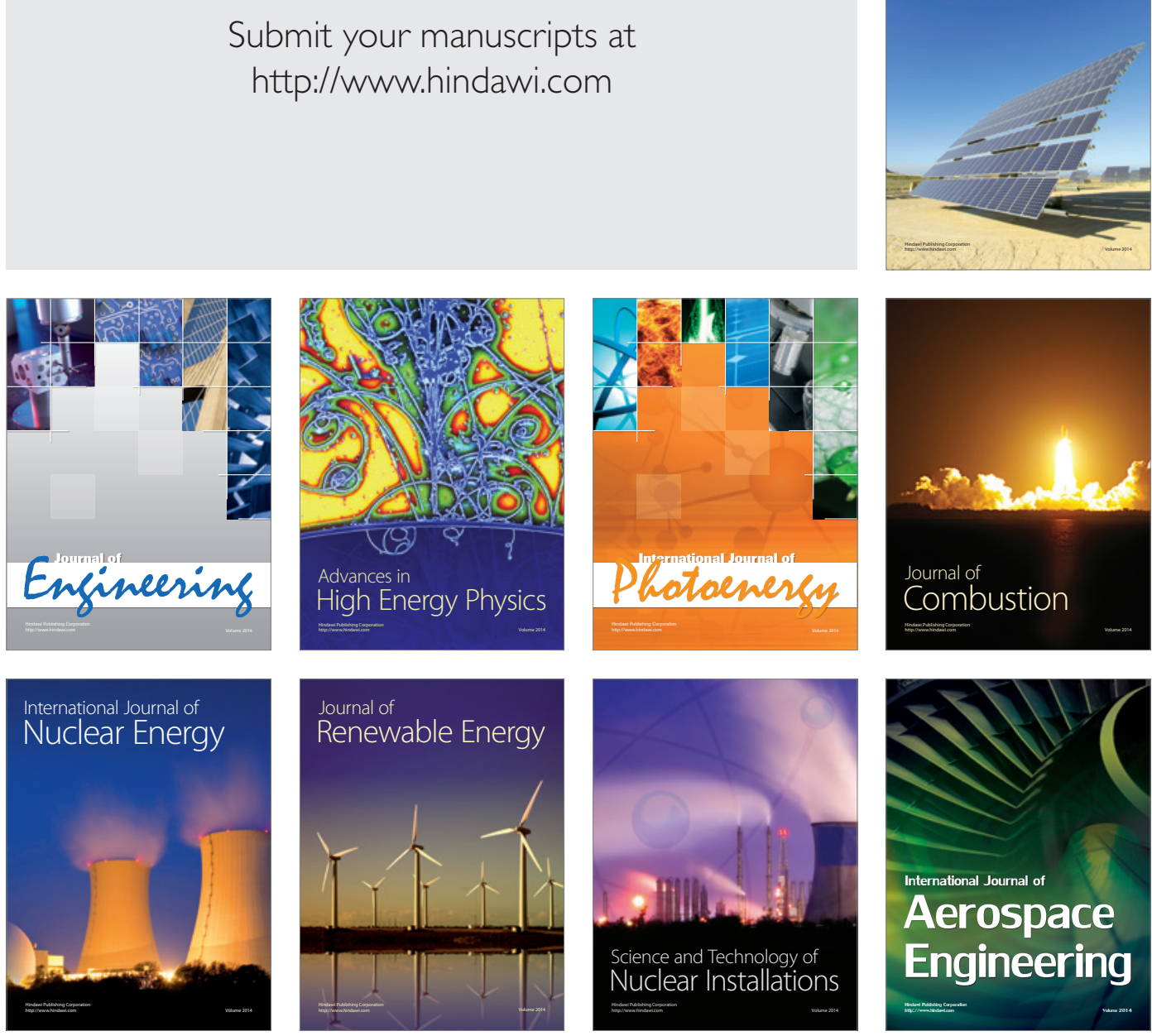